\title{
THE RISK MEASUREMENT OF CHINA'S CARBON FINANCIAL MARKET: BASED ON GARCH AND VAR MODEL
}

\author{
WANG, L. ${ }^{*}-$ TANG, $^{2}{ }^{2}-$ QIU, X. M. ${ }^{1}-$ ZHANG, X. X. ${ }^{2}-$ MA, R. H. ${ }^{1}$ \\ ${ }^{I}$ Economic and Trade College, University of Electronic Science and Technology of China \\ Zhongshan Institute, Zhongshan 528499, China \\ ${ }^{2}$ Management College, University of Electronic Science and Technology of China \\ Zhongshan Institute, Zhongshan 528499, China \\ ${ }^{*}$ Corresponding author \\ e-mail:838241358@qq.com; phone: +86-1591-7293-187 \\ (Received $3^{\text {rd }}$ Apr 2019; accepted $17^{\text {th }}$ May 2019)
}

\begin{abstract}
By studying five carbon emission exchanges (Beijing, Shanghai, Shenzhen, Guangdong, and Hubei) within China, this study uses the GARCH model to explore the price volatility characteristics of regional carbon trading markets and measures the trading market risks based on VaR model. The results show that the adopted GARCH $(1,1)$ risk model fits well with the characteristics of returns. Besides, fluctuation shock varies among different exchanges, and the volatility of carbon price is influenced more by the heterogeneity of the external environment of the carbon market than the role of internal market mechanisms. The value-at-risk varies between exchanges. These findings pose more challenges to the risk monitoring of carbon finance markets. Therefore, the current work attempts to recommend the establishment of a unified national carbon trading market to control risks and maintain stable market development.
\end{abstract}

Keywords: carbon finance, VaR, GARCH, ARCH-LM test, Kupiec failure frequency test

\section{Introduction}

Carbon dioxide is the main factor causing the greenhouse effect. With the advances of economic development, China's carbon dioxide emission have become one of the highest in the world. As a result, while China is facing huge pressure for emissions reduction, it has also generated the conditions and foundations for building a carbon market. The market mechanism is an effective method to save energy and reduce emissions. Since the enforcement of the Kyoto Protocol, western developed countries have established carbon trading markets that target carbon dioxide emission producers. The largest and most developed is the European Union Emission Trading Scheme (EUETS), established in 2005. Additionally, the development of international carbon finance market has proven that the emissions trading theory in economics is indeed effective in combating climate change. As one of the largest global carbon resource holders, China is also one of the largest carbon emission suppliers in the carbon market. Since November of 2013, China has successively established eight pilot carbon exchanges, in Shenzhen, Beijing, Shanghai, Hubei, Tianjin, Guangdong, Chongqing, and Fujian. Their total trading volume has already reached 14,000 tons, calculated from the commencement of carbon emission trading, by April 2018, and the total turnover exceeded 2.5 billion CNY. With the expansion of trade scale and the continuous improvement of trading operation mechanisms, these trading markets could play a more significant role in China's energy conservation and emission reduction tasks. 
Carbon finance refers to the transformation of carbon emission rights into a commodity that meets international certification standards via market-oriented tools and means for trading. The research on carbon finance risks started by focusing mainly on the classification and influencing factors of carbon trading risks. Regarding the classification and definition of carbon trading risks, Larson and Parks (1999) clarified that the trading risk of carbon finance exists in many aspects such as project preparation, implementation, evaluation, approval, secondary market, and target market. They analyzed the types of trading risks, and classified them into three types: performance risk, price risk, and policy risk. When qualitatively analyzing carbon emission reduction projects, Laurikka and Springer (2003) classified the ones into six categories, of which, the price risk, cost risk, and quantity risk were the primary risks. Dutschke et al. (2004) categorized the clean development mechanism (CDM) risks into three types: baseline estimation risk, commercial risk, and institutional risk. Regarding the research on the impact of carbon trading risk, Mansanet-Bataller et al. (2010) adopted a multivariate approach to analyze the risks from the perspective of carbon price fluctuations. Their results show that the carbon price was significantly influenced by energy prices and extreme weather. Carmona et al. (2010) found that the long-term and short-term emission reduction projects affected the price volatility of carbon emission allocations in varying ways, and that the energy price trends and the factors influencing carbon emissions (e.g. weather, power plant interruption accidents, etc.) were also closely related to the volatility of carbon prices. Additionally, scholars including Alberola et al. (2008), Kijima et al. (2010), Ibrahim and Kalaitzoglou (2006), and Labatt and White (2011) have also conducted related research.

In China, the carbon trading markets, compared to the western countries, was established much later. Wang and Song (2009) classified the carbon finance risks into three categories, namely the operational risks of carbon financial derivatives, the political risks of carbon finance, and the economic risks of macro-economy. According to Sun (2015), the risk structure of carbon finance market is constituted primarily by uncertain policy risks, liquidity risks, and political risks, while the major causes of these included inadequate supporting policies and laws, uncertain future international situation, insufficient knowledge of entities, lack of professionals, and imperfect service system of carbon finance organizations.

In general, despite the differing classifications of carbon trading risks by domestic and foreign experts, scholars, and organizations, all the risk types are encompassed within two major categories of non-systematic risks and systemic risks. In terms of riskinducing influences, including weather, energy prices, project emission reduction cycles, macro factors, trading systems, etc. The remainder of this study is organized as follows: Section 2 describes the model setup; Section 3 presents the data description and validation; Section 4 is the empirical analysis and the last Section provides conclusions.

\section{Materials and Methods}

\section{Methods}

There are two major market risks faced by carbon finance trading entities in the market. One is the change in market size and the other is the fluctuation of carbon emission rights price. In addition, these two are mutually dependent. The change in market size can cause price fluctuations, and its risk is ultimately reflected in the price 
volatility risk. This study assesses the risk of carbon finance market by measuring the price volatility risk.

\section{Market risk and VaR model}

The portfolio theory proposed by Markowitz (1952) in 1952 marks beginning of market risk quantification in the risk research, in which, he measured the risk level of a financial product using the mean of returns divided by the variance. With the increasing maturity of risk research in recent years, the value at risk $(\mathrm{VaR})$ measure has been the primary choice for academia in researching risk management. VaR refers to the maximum possible loss of a financial asset during the holding period at a certain confidence level under normal market fluctuations. Its value represents the level of market risk quite concisely. According to its definition, $\mathrm{VaR}$ is expressed as:

$$
\operatorname{Prov}(\Delta \mathrm{P}>\operatorname{VaR})=1-\alpha
$$

where, $\Delta \mathrm{P}$ denotes the loss of a financial asset within the holding period $\Delta \mathrm{t}$; VaR denotes the value at risk under confidence level of 1- $\alpha$. Suppose that the initial price of a financial asset is $P_{0}$, and the rate of return is $R$, then the ending price is $P=P_{0} \times(1+R)$. When expected value and volatility of the return $\mathrm{R}$ are $\mu$ and $\mathrm{e}$, respectively, then the minimum value of the financial asset at a given confidence level is $\mathrm{P}^{*}=\mathrm{P}_{0} \times\left(1+\mathrm{R}^{*}\right)$. Hence:

$$
\mathrm{VaR}=\mathrm{E}(\mathrm{P})-P^{*}=E\left(P_{0} \times(1+R)\right]-P_{0}\left(1+R^{*}\right)=-P_{0} \times\left(R^{*}-\mu\right)
$$

Calculation of $\mathrm{VaR}$ on this basis is equivalent to determining the minimum value $\mathrm{P}^{*}$ or the minimum rate of return $R^{*}$.

The above process describes a general approach to calculating VaR. In practice, the VaR solutions are classified into historical standard deviation methods, Risk Metrics, ARCH methods, etc., depending on how the market factor volatility is estimated. It is more reasonable to use the GARCH model from the ARCH family for financial time series with high peak and heavy tail characteristics.

\section{GARCH model and EGARCH}

Engle (1982) proposed an ARCH (autoregressive conditional heteroskedasticity) model to avoid the influences of conditional heteroskedasticity in time series on empirical results. The canonical form of the $\mathrm{ARCH}(\mathrm{q})$ model is as follows:

$$
\sigma_{t}^{2}=\alpha_{0}+\sum_{i=1}^{q} \alpha_{i} \varepsilon_{t-i}^{2}
$$

where, $\sigma_{t}^{2}=\operatorname{Var}\left(\varepsilon_{t} \mid \Omega_{t-1}\right)$ presents all information of conditional variance $\Omega_{t-1}$ at and before time $\mathrm{t}-1$. In accordance with the $\mathrm{ARCH}$ model, the conditional variance of random error $\mathrm{u}_{t}$ depends on its previous value of $\mathrm{u}_{t-1}$.

However, in practical application the ARCH model tends to require a higher lag order, which leads to increased number of parameters under estimation, thereby affecting the accuracy of estimations. To address this problem, Bollerslev et al. (1986) proposed the GARCH (generalized autoregressive conditional heteroskedasticity) model based on the research conducted by Engle, which is as follows: 


$$
\begin{gathered}
R_{\mathrm{t}}=\mu_{t}+\varepsilon_{t} \quad t=1,2, \ldots, T \\
\sigma_{t}^{2}=\alpha_{0}+\sum_{i=1}^{q} \alpha_{i} \varepsilon_{t-i}^{2}+\sum_{j=1}^{p} \beta_{j} \sigma_{t-j}^{2}
\end{gathered}
$$

Among the above formulas, the mean equation presented in $E q .4$ is an exogenous function with an error term. The establishment of this equation can directly eliminate linear correlation between the antecedent and consequent terms of the series. Eq. 5 is a conditional variance equation, where $\varepsilon_{t-i}^{2}$ denotes the square of lag random error in the mean equation. It is the volatility information in the initial measurement period, which is also considered as the ARCH term. $\sigma_{t-j}^{2}$ denotes the forecast variance of the previous period, i.e. the GARCH term. $\sigma_{t}^{2}$ can be considered as a positive weighted average of the previous residuals, which is consistent with the volatility clustering. To be specific, large volatility may lead to greater changes; conversely, small volatility may cause small changes. The $\operatorname{GARCH}(1,1)$ model is the most typically used in practical application.

However, the disadvantages of GARCH model are that it strictly restricts the nonnegativity of coefficient parameters, and fails to reflect the leverage effect of financial market, thus easily leading to deviations when applied in the financial market. The EGARCH (exponential GARCH) model overcomes the above deficiencies effectively and thus it is more widely used in present financial research. The expression for the conditional variance of EGARCH model is:

$$
\ln \sigma_{t}^{2}=\alpha_{0}+\sum_{i=1}^{p} \alpha_{i}\left|\frac{\varepsilon_{t-1}}{\sigma_{t-1}}-E\left(\frac{\varepsilon_{t-1}}{\sigma_{t-1}}\right)\right|+\sum_{k=1}^{r} \gamma \frac{\varepsilon_{t-k}}{\sigma_{t-k}}
$$

Using natural logarithm as the conditional variance, the EGARCH model illustrates that the expressive form of leverage effect is exponential. The model also introduces a parameter $\gamma$. If $\gamma=0$, it indicates that the volatilities produced by the price rising and falling symmetrically are identical. If $\gamma>0$, it indicates that the volatility by price rising is greater than that by price falling, and vice versa if $\gamma<0$.

A key issue in ARCH family models is the choice of error term distribution. In research, normal distribution is usually taken as an assumption. However, in practice, the tail of unconditional distribution for financial time series is often wider than the normal distribution. Therefore, normal distribution is incapable of accurately reflecting the tail characteristics of residual distribution, while the $t$ distribution and the GED (generalized error distribution) can preferably capture the heavy tailed phenomenon. In the following, we separately obtain the log-likelihood functions of the standard normal distribution, GED, and $t$ distribution by denoting the parameter vector by $\theta$ as follows:

(1) The log-likelihood function of the GARCH $(1,1)$ model whose residuals follow normal distributed is:

$$
\ln L(\theta)=-\frac{T}{2} \ln (2 \pi)-\frac{1}{2} \sum_{t=1}^{T} \ln \sigma_{t}^{2}-\frac{1}{2} \sum_{t=1}^{T} \varepsilon_{t}^{2} / \sigma_{t}^{2}
$$

The variable $\sigma_{t}^{2}$ is the conditional variance of $u_{t}$.

(2) The log-likelihood function of the GARCH $(1,1)$ model whose residuals follow GED is: 


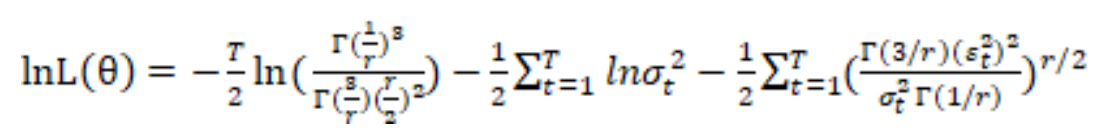

where, $\Gamma(\cdot)$ is a Gamma function. When the parameter $\mathrm{r}=2$, the GED becomes a normal distribution; when $\mathrm{r}<2$, the GED has a heavier tail than the normal distribution; when $\mathrm{r}>2$, the GED has a lighter tail than the normal distribution.

(3) The log-likelihood function of the GARCH $(1,1)$ model whose residuals follow student's t distribution is:

$$
\operatorname{lnL}(\theta)=-\frac{T}{2} \ln \left(\frac{\pi(\mathrm{k}-2) \Gamma(\mathrm{k} / 2)^{\mathrm{n}}}{\Gamma[(\mathrm{k}+1) / 2]^{\mathrm{a}}}\right)-\frac{1}{2} \sum_{t=1}^{T} \ln \sigma_{t}^{2}-\frac{k+1}{2} \sum_{t=1}^{T} \ln \left(1+\frac{\varepsilon_{t}^{\mathrm{B}}}{\sigma_{t}^{\mathrm{T}}(\mathrm{k}-2)}\right)
$$

The parameter estimation in $E q .9$ is in actual the problem of maximizing the loglikelihood function under a degree of freedom $k>2$ constraint. When $k \rightarrow \infty$, the $t$ distribution approaches a normal distribution.

\section{Materials}

\section{Selection of sample data}

Currently, spot market enjoys the largest trading volume in China's carbon finance market based on the data consisting mainly of the trading volumes and turnovers of eight pilot carbon emission exchanges. The analysis of these data allows us to understand the risk profile of the carbon finance market. In view of the differing establishment time of China's carbon finance pilots, the daily trading volume and turnover data from January 2016 to April 2018 (totaling 563 trading days) are selected in the proposed study. Since the data from pilot sites in Chongqing, Fujian, and Tianjin are comparatively smaller and lacks statistical significance, modeling analysis is not performed herein for these three regions. The data used in the current study comes from the Chinese carbon trading website.

\section{Statistical characteristics of return series for various exchanges}

(1)Trend analysis of return time series

Establishment of a return index for the carbon finance market is attempted by utilizing the daily data from the above carbon emission exchanges. The average transaction price $\mathrm{P}_{\mathrm{t}}$ of sample data is represented by the ratio of the current day's turnover to the current day's volume. Considering the stability of data, the rate of return $\mathrm{R}_{\mathrm{t}}$ is represented by the logarithmic form as follows:

$$
\mathrm{R}_{\mathrm{t}}=\ln \mathrm{P}_{\mathrm{t}}-\ln \mathrm{P}_{\mathrm{t}-1}
$$

The EVIEWS 10.0 software is employed to plot the time series graph of returns (Figure 1). Obviously, the logarithmic returns for the five pilot exchanges all fluctuate around zero. When the fluctuations are large, the changes in successive periods are larger; when the fluctuations are small, the changes in successive periods are smaller, exhibiting a distinct "volatility clustering" effect.

(2) Normality test

The Jurque-Bera statistic is a commonly used method for testing normal distribution and its calculation formula is as follows: 


$$
\mathrm{JB}=\frac{n}{6}\left[S^{2}+\frac{(K-3)^{2}}{4}\right]
$$

where, $\mathrm{n}$ is the sample size, $\mathrm{S}$ is the skewness, and $\mathrm{K}$ is the kurtosis. Under the normality assumption, JB obeys $\chi^{2}(2)$ distribution, with a critical value of 5.99147 at a $5 \%$ significance level. If the JB statistic exceeds its critical value, the null hypothesis of normal distribution will be rejected. Table 1 lists the JB statistics (Eq. 11) calculated by EVIEWS 10.0. As the JB statistics for the five pilot exchanges are all considerably above the critical values, the returns of the exchanges all show obvious non-normality. Table 1 shows that the kurtoses of the five pilot sites are all greater than 3 and the skewness are different from 0 . Therefore, the return curves present a "sharp peak and heavy tail" distribution features.

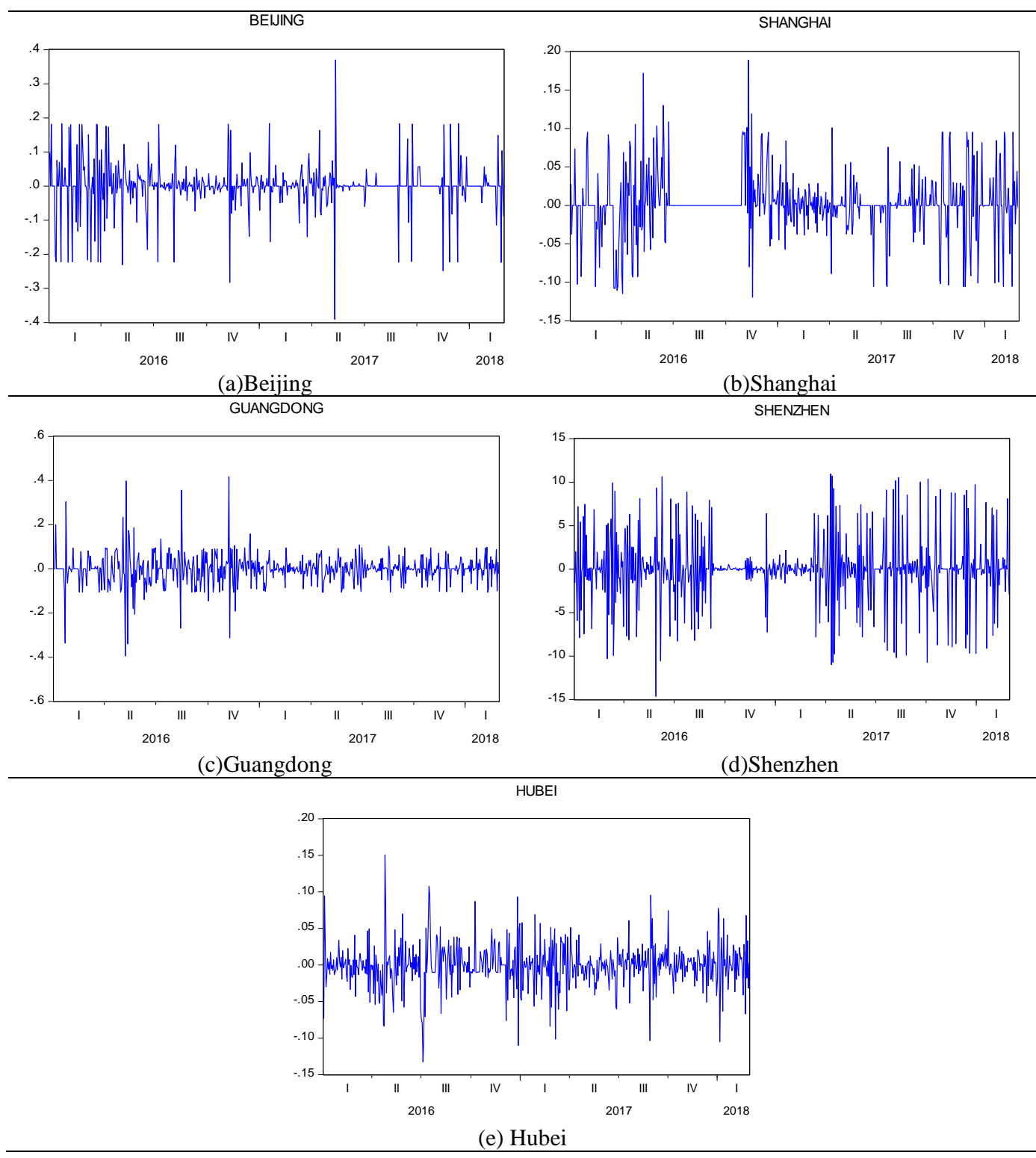

Figure 1. Rate of return trend in carbon trading market 
(3) Stationary test for logarithmic returns of various carbon exchanges

The stationarity test results with augmented Dickey-Fuller (ADF) test are shown in Table 2, showing that return series of the five pilot sites all reject the null hypothesis that "there exists at least one unit root" at the $1 \%$ significance level, suggesting that the logarithmic returns of the five pilot sites are stationary series.

(4) Heteroscedasticity test

A Lagrange Multiplier (LM) is then used to perform the lag ARCH test on the residuals of mean equations for the five carbon trading exchanges, and the results are shown in Table 3. The $\mathrm{p}$ values of the F statistic and the Obs* $\mathrm{R}$-squared statistic are all close to zero, and the results all reject the null hypothesis, indicating the presence of heteroskedasticity in the returns of various pilot sites. The heteroskedasticity can reflect the extreme price fluctuations and extreme risks of carbon exchanges in various regions. This suggests that China's carbon finance market may be at risk, which necessitates its risk analysis.

Obviously, the p-value is zero after the squared residuals of returns, for various exchanges lag a certain order; therefore, the null hypothesis is rejected. The ARCH effect is considered to exist in the residual series of each exchange's regression model.

Table 1. Normality test

\begin{tabular}{c|c|c|c|c|c}
\hline Item & Beijing & Shanghai & Guangdong & Shenzhen & Hubei \\
\hline JB statistic & 1061.912 & 169.4251 & 1944.742 & 68.7976 & 223.5930 \\
skewness & -0.6903 & 0.1561 & 0.0706 & -0.0769 & -0.0699 \\
kurtosis & 9.585 & 5.6693 & 0.1198 & 4.7056 & 6.0841 \\
\hline
\end{tabular}

Table 2. ADF Test at the 1\% significance level

\begin{tabular}{c|c|c|c|c|c}
\hline Item & Beijing & Shanghai & Guangdong & Shenzhen & Hubei \\
\hline ADF test statistic & -23.9183 & -21.7936 & -21.6165 & -16.4819 & -26.5245 \\
Test critical values & -3.441777 & -3.441757 & -3.441777 & -3.441840 & -3.441757 \\
Prob. ${ }^{*}$ & 0.0000 & 0.0000 & 0.0000 & 0.0000 & 0.0000 \\
\hline
\end{tabular}

Table 3. ARCH-LM Test

\begin{tabular}{c|c|c|c|c|c}
\hline Exchange & Lag Rank & F statistic & p-value & T $\times$ R2 statistic & p-values \\
\hline Beijing & 1 & 39.03165 & 0.0000 & 36.61471 & 0.0000 \\
Shanghai & 7 & 48.21587 & 0.0000 & 44.54611 & 0.0000 \\
Guangdong & 3 & 63.60045 & 0.0000 & 57.30778 & 0.0000 \\
Shenzhen & 2 & 9.513342 & 0.0001 & 18.49639 & 0.0001 \\
Hubei & 1 & 207.5346 & 0.0000 & 151.8873 & 0.0000 \\
\hline
\end{tabular}

\section{Results}

In the current study, the lag order of $\mathrm{ARCH}(\mathrm{p})$ and calculation of the $\mathrm{AC}$ and PAC for the residuals sum of squared of regression models coefficients were used in the Eviews 10.0 software. The results show that the AC and PAC are significantly non-zero, while the Q statistics are highly significant. Therefore, the research method of this paper is identified as $\operatorname{GARCH}(1,1)$. 


\section{Parameter estimations by GARCH and EGARCH models}

The GARCH(1,1) (Eq. 5) under standard normal distribution (Eq. 7), GED (Eq. 8), and t-distribution $(E q .9)$ are used separately herein to perform parameter estimation on the five carbon trading exchanges' returns. Table 4 displays the most suitable method. It is found that the GED is most appropriate for residuals distribution of the four exchanges except for Guangdong, where the adjustment of tail bias with normal distribution is needed.

According to the estimations in Table 4, the mean value is the greatest for Beijing, and the least for Shanghai. The reason may be that Beijing has a large market volume and faces great risks. By contrast, the trading volume in Shanghai has been quite low in the past two years, so it is at a smaller risk. In addition, Shanghai exchange's return shock decays the slowest, followed by Hubei.

Table 4. Parameter estimations at GARCH(1,1) and EGARCH(1,1) models

\begin{tabular}{|c|c|c|c|c|c|}
\hline Parameter & Beijing & Shanghai & Guangdong & Shenzhen & Hubei \\
\hline \multicolumn{6}{|c|}{ Mean equation } \\
\hline $\mathrm{AR}(2)$ & $\begin{array}{c}-0.418418 \\
(0.0000) \\
-0.321769 \\
(0.0000) \\
\end{array}$ & $\begin{array}{c}-0.009039 \\
(0.0000)\end{array}$ & $\begin{array}{c}-0.271687 \\
(0.0000) \\
-0.142413 \\
(0.0044) \\
\end{array}$ & $\begin{array}{c}-0.201236 \\
(0.0000)\end{array}$ & $\begin{array}{c}-0.172881 \\
(0.0000)\end{array}$ \\
\hline \multicolumn{6}{|c|}{ Variance equation } \\
\hline$\alpha$ & $\begin{array}{c}0.000848 \\
(0.0042)\end{array}$ & $\begin{array}{c}8.98 * 10-14 \\
(0.0000)\end{array}$ & $\begin{array}{c}0.000834 \\
(0.0000)\end{array}$ & $\begin{array}{c}0.046786 \\
(0.0000)\end{array}$ & $\begin{array}{c}0.000264 \\
(0.0000)\end{array}$ \\
\hline$\alpha_{i}$ & $\begin{array}{c}0.128381 \\
(0.0154)\end{array}$ & $\begin{array}{c}0.320059 \\
(0.0000)\end{array}$ & $\begin{array}{c}0.565035 \\
(0.0000)\end{array}$ & $\begin{array}{c}0.698226 \\
(0.0727)\end{array}$ & $\begin{array}{c}0.616326 \\
(0.0003)\end{array}$ \\
\hline$\beta$ & $\begin{array}{c}0.367891 \\
(0.0280)\end{array}$ & $\begin{array}{c}0.485901 \\
(0.0000)\end{array}$ & $\begin{array}{c}0.395047 \\
(0.0000)\end{array}$ & $\begin{array}{c}-0.041038 \\
(0.3810)\end{array}$ & $\begin{array}{c}0.189103 \\
(0.0688)\end{array}$ \\
\hline$v$ & $\begin{array}{c}0.017480 \\
(0.0000)\end{array}$ & $\begin{array}{c}0.284511 \\
(0.0000)\end{array}$ & $0 \#$ & $\begin{array}{c}0.614986 \\
(0.0000)\end{array}$ & $\begin{array}{c}1.051873 \\
(0.0000)\end{array}$ \\
\hline$\gamma$ & $\begin{array}{c}0.102220 \\
(0.0026)\end{array}$ & $\begin{array}{c}-0.033219 \\
(0.1139)\end{array}$ & $\begin{array}{r}0.090221 \\
(0.0091)\end{array}$ & $\begin{array}{c}-0.204153 \\
(0.0471)\end{array}$ & $\begin{array}{c}-0.026748 \\
(0.7711)\end{array}$ \\
\hline AIC & -17.09388 & -8.639286 & -2.774323 & -0.471930 & -4.552960 \\
\hline SC & -17.04757 & -8.600750 & -2.735734 & -0.433394 & -4.514424 \\
\hline
\end{tabular}

Note: \# indicates that the residual series uses a normal distribution to adjust the tail bias

Concerning the variance models, all $\alpha$ and $\beta$ values are significant at a significance level of $10 \%$ aside from the insignificant $\beta$ value for Shenzhen, indicating that these models can well depict the volatility clustering feature of the returns in various carbon trading markets. The $\alpha$ value represents the impact of the external market environmental factors on the rate of return, while the $\beta$ value represents the impact of return volatility on itself. Greater $\beta$ value indicates longer effect of the return volatility on itself, i.e. the presence of long-term memory effect. Based on Table 4, it can be seen that Shanghai has the largest $\beta$ value of 0.485901 , indicating that the $48.5901 \%$ of the variance impact in the current period will continue to exist in the next period. This suggests that the decay of the impact is the slowest for Shanghai, followed by Beijing and Guangdong. The risks faced by the three exchanges in Guangdong, Shenzhen, and Hubei are mainly from the impact of external shocks $\left(\alpha_{\mathrm{i}}>\beta\right)$, indicating that the heterogeneity of the external environments for these three markets is more influential to the carbon price volatility than the role of internal market mechanism. For Beijing, on the contrary, the risks mainly come from internal market mechanism. The $\alpha$ values of the five exchanges are significantly less than 1 , with $\alpha i+\beta<1$. This indicates that the fluctuation of return 
attenuates gradually in response to externalities, and that both external factors and internal impact have slow disappearing influences on the rate of return. Shanghai exhibits the largest $\beta$ value, followed by Guangdong and Beijing. This shows that the return volatilities of these three exchanges have a long-term impact on themselves, which possess a certain memory effect. The $\gamma$ coefficients are significantly non-zero for all exchanges other than Hubei, where the value is insignificant. Beijing, Shanghai, and Guangdong exhibit positive $\gamma$ coefficients, indicating that the impact of positive rate of return for carbon finance is greater than the negative shock of the same degree, whereas, an opposite trend is observed for Shenzhen.

\section{Daily VaR values for various exchanges}

The daily VaR values at a 95\% confidence level are calculated using the conditional variance of the above models, and the statistical results are presented in Table 5.

Table 5. The calculation results at the VaR model

\begin{tabular}{c|c|c|c|c|c|c|c|c}
\hline Exchange & Min. & Max. & Mean & $\begin{array}{c}\text { Standard } \\
\text { deviation }\end{array}$ & $\begin{array}{c}\text { Failed } \\
\text { days }\end{array}$ & Failed rate & LR statistic & $\begin{array}{c}\text { LR critical } \\
\text { value* }\end{array}$ \\
\hline Beijing & -1.199 & -0.0879 & -0.3 & 0.13918 & 3 & $0.535 \%$ & 0.6413 & 6.635 \\
Shanghai & -0.314 & $-9 \times 10^{-7}$ & -0.0629 & 0.05752 & 8 & $1.424 \%$ & 0.3908 & 6.635 \\
Guangdong & -1.857 & -0.1508 & -0.2834 & 0.17172 & 2 & $0.357 \%$ & 1.354 & 6.635 \\
Shenzhen & -6.385 & -0.1692 & -1.8937 & 0.31346 & 5 & $0.89 \%$ & 0.0312 & 6.635 \\
Hubei & -1.919 & -1.3664 & -1.6794 & 0.10021 & 0 & $0 \%$ & - & 6.635 \\
\hline
\end{tabular}

*: at a $1 \%$ significant level

We can determine the market volatility of exchanges based on the standard deviations of daily $\mathrm{VaR}$ values. The greater the standard deviation, the higher the volatility of market. As shown in Table 5, Shenzhen has the highest volatility, whereas Shanghai is the lowest. The exchanges can be arranged in a descending order of volatility as Shenzhen> Guangdong> Beijing> Hubei> Shanghai. Shenzhen's trading volume and turnover are second only to Hubei among the five pilot sites, and its mean $\mathrm{VaR}$ is the largest. This is mainly attributed to the abnormally large standard deviations resulting from the large fluctuations of individual average transaction prices.

\section{Results of Kupiec failure frequency test}

Kupiec (1995) proposed a failure frequency test to posteriorly testify and evaluate $\mathrm{VaR}$ efficiency. Its procedure is as follows: Assuming that the significant level is $\alpha$, and the actual loss is $\triangle \mathrm{P}=\mathrm{P}_{\mathrm{t}}-\mathrm{P}_{\mathrm{t}-1}$, failure is considered when $\triangle \mathrm{P}>\mathrm{VaR}$. The number of inspection days is denoted by $\mathrm{T}$, the number of failed days is denoted by $\mathrm{N}$, and the frequency of failure is denoted by $\mathrm{P}=\mathrm{N} / \mathrm{T}$. At a significance level of $\alpha$, the expected failure probability is $\mathrm{E}(\mathrm{P})=\mathrm{P}^{*}=1-\alpha$. The "likelihood ratio test" is adopted for failure detection, whose mathematical expression is

$$
\mathrm{LR}=-2 \log \left[\left(1-p^{*}\right)^{(T-N)}\left(p^{*}\right)^{N}\right]+2 \log \left[\left(1-\frac{N}{T}\right)^{(T-N)}\left(\frac{N}{T}\right)^{N}\right.
$$

where, the LR statistic follows $\chi 2(1)$, with a critical value of 6.635 at a $1 \%$ significant level. If the LR value is greater than 6.635, the VaR model is considered invalid. Smaller LR value indicates a more effective model, which can more easily pass the test. 
Table 5 shows the calculations by Eq. 12. At a $99 \%$ confidence level, the results of Kupiec failure frequency test for the five exchanges do not reject the null hypothesis, so the model is valid. Thus, the GARCH-VaR risk model used in this paper can well fit the characteristics of returns.

\section{Discussion}

The carbon trading market currently consists of the allocation market (primary market), the spot market (secondary market), and the derivatives market. Among them, the allocation market is responsible for the total amount setting and the initial allocation of allowances, whose chief function is to create carbon allowances. The spot market is a place for spot trading of allowances, which plays the role of basic price discovery and resource circulation. The derivatives market is a place for trading carbon futures, carbon options and other carbon financial derivatives, whose role is to further deepen price discovery, hedging and to avoid risks. Different levels of markets face varying risks, which need to be analyzed separately.

\section{Allocation market risks}

The function of allocation market is to create products and provide a basis of trading. Its risks mainly exist in the following aspects:

\section{Total carbon allowance setting risk}

Total carbon allowance setting risk refers to the risk brought by drastic fluctuations of carbon allowance price due to the unreasonable total allowance setting by the government. Unreasonable total allowance setting includes both excessive and overtight setting. Excessive allowance setting will lead to weakened incentive mechanism for emission reduction, so that businesses do not have enough incentive to reduce emissions. Over-tight allowance setting, on the other hand, will lead businesses to bear excessively high cost, thus affecting their competitiveness. In its first stage, EUETS caused carbon price slump due to the excessive allowance issuance, where the price was close to zero. Thus, how to determine the issuing amount will affect the price of carbon market.

\section{Carbon allowance allocation risk}

Carbon allowance allocation, which is closely related to the total amount setting, refers to the government's allocation of allowances to businesses by ways like free distribution and paid auctions. The allowance allocation risk is the risk brought about by the unfair distribution of allowances, which is attributable mainly to the defects in the allowance approval procedure. Currently, the common approval methods in the carbon trading market are the Grandfather clauses and the Industry baseline, which have respective advantages and disadvantages. The advantage of the grandfather clauses is that it considers the historical fairness, but its disadvantage is that the reliability of future prediction using historical data is not high. Meanwhile, the Industry baseline often determines a benchmark based on industry-leading levels, and the portion that is superior to the benchmark is eligible for free allowances, while the portion inferior to the benchmark requires purchase of allowances. The advantages of this method are that it encourages technological improvement and the promotion and popularization of 
advanced technologies. Its disadvantage is the complicated and costly process of determining the baseline.

\section{Carbon leakage risk}

Carbon leakage refers to a situation in which the businesses in countries with strict environmental policies shift to countries without strict environmental policies to trigger rising carbon emissions in the migrant countries. The occurrence of carbon leakage stems mainly from concerns about production cost increase. The carbon leakage problem is inevitable as long as the environmental policies of various countries are inconsistent. Due to the territorial feature of the carbon emission system, environmental policies often have an effect only on domestic companies, but are powerless to foreign companies. Therefore, domestic companies have a strong incentive to transfer production to other countries that are not strictly implementing environmental policies for cost reduction purposes, thereby resulting in the carbon leakage.

\section{Spot market risks}

Spot market, also known as the secondary market, is an important part of the carbon trading market. The risks in the spot market mainly include: performance risk and illegal operation risk.

\section{Performance risk}

Performance risk refers to the possibility of loss to the one trading party who has fulfilled the transactional obligation after conclusion of a carbon allowance transaction (trading) caused by the failure of the other party to perform the payment obligation in accordance with the transaction contract. Aside from involving qualifications and integrity of both parties, the performance risk sources may also cover the entire trading system. This necessitates checking the transaction system of carbon trading market in an all-round way, including whether the allowance allocation is too loose or too tight; whether the carbon emission monitoring, reporting and verification system is sound; whether the market operation is effective, etc.

\section{Illegal operation risk}

Illegal operation risks can generally be classified into the following categories: The first category is serious crimes using the carbon market as a tool, such as fraud, money laundering, and terrorist financing. The most famous events were the phishing involving carbon emissions rights across Europe, Japan and New Zealand that was uncovered in Germany in February 2010, and a VAT carousel fraud took place in the UK in June 2012. The second category is financial market violations, including market manipulation, insider dealing, etc.

\section{Derivatives market risks}

Derivatives market, also known as the tertiary market, faces many risks due to the complexity of trading derivatives such as futures and options. Based on the early development experience of global carbon trading market, these risks mainly include: liquidity risk, credit risk and investor risk. 


\section{Liquidity risk}

Liquidity risk is classified into the market liquidity risk and the financial liquidity risk. The former is mainly reflected in the insufficient market trading volume or inactive market transactions, whose essential cause is the inadequate market depth and breadth. The financial liquidity risk refers to the possibility that the investor is unable to fulfill the payment obligation upon contract expiration due to lack of current funds, or meet margin calls in accordance with the contract at the time of settlement. Rather than existing in isolation, liquidity risk is often accompanied by other risks. Sometimes, however, it may also mean that the trading mechanism itself is flawed.

\section{Credit risk}

Credit risk, also known as default risk, refers to the possibility of loss to one trading party caused by refusal of the other party to perform the agreed terms. The emergence of credit risk is often related to the immature carbon trading market and the imperfect relevant systems.

\section{Investor risk}

Investor risk is mainly reflected in the influences of unreasonable structure and poor quality of investors on the operation of carbon trading market. Investors are classified into the institutional investors and the individual investors. In mature markets, institutional investors should account for a larger proportion. In the current stage, investor risk is mainly concentrated in the derivatives market. This necessitates setting reasonable thresholds and conditions for investors participating in the carbon derivatives trading, so as to ensure the effective linkage and functioning of the carbon trading markets at various levels.

\section{Policy suggestions}

The successive establishment of carbon trading markets in China is of milestone significance to the development of China's carbon finance market, which shows that China has begun to seek the dynamic balance between low-carbon economic development, corporate growth, and eco-environmental protection via market and price mechanisms. Ensuring the orderly fluctuations in China's carbon trading prices guarantees the effective monitoring and control of carbon finance market risks and promotes the stable development of the carbon finance market. We put forward the following suggestions:

Firstly, it is necessary to enhance the rationality of policies, thus gradually integrating the carbon market. Since China's eight major pilot sites for carbon emission trading have taken the lead in accumulating experience, the industries covered by all or most of these sites, such as the power and cement industries, should be the first to be considered for integration. In the meanwhile, a unified quota system should be implemented for the emission control firms of these industries. On the basis of vigorously advancing the pilot sites for carbon emission trading, a unified national control over total quantity should be practiced. Furthermore, quota should be allocated based on factors like regional GDP and carbon emission demands, and a carbon quota trading mechanism should be established to foster a fair and active carbon trading market. 
Secondly, it is necessary to improve the level of risk management as well to monitor and control risks: 1. Perfecting the legal framework, and standardizing the carbon trading market system. The regulatory issues involving the carbon finance market must be addressed by legal means. Regulations related to the construction of carbon trading markets should be legislated to enable the stable and orderly development of the carbon finance market. The strong policy dependence of carbon finance itself determines that it is necessary to legally clarify the institutional arrangements for the carbon trading markets, and to incorporate risk issues into the legal context in order to adjust interest relationships, regulate carbon markets, and control risks. 2. The close monitoring of carbon price fluctuations and establishment of a risk measurement system. The GARCH-VaR model established in this paper has certain referential significance in measuring market risk. The supervisory authorities should thus establish a risk measurement system, and set a daily VaR monitoring value for each market to serve as a "risk pre-warning line", so as to improve the early warning capability against risks.

Finally, construction of carbon trading market infrastructures should be strengthened. Respecting the construction of primary carbon trading market (carbon allowance approval, issuance, etc.), the development of greenhouse gas inventory and the construction of statistical accounting systems should be accelerated. It is necessary to prioritize the establishment of greenhouse gas reporting systems for key industries, and establish a sound auction procedure to ensure the smooth delivery of carbon emission rights. Concerning the secondary carbon trading market (spot trading), the role of the carbon emission rights registration system should be played to enhance the market liquidity and improve the trading efficiency. As for the carbon futures market, formulation of carbon futures trading rules covering market participants, delivery system, and price formation mechanism is necessary by learning from the useful international experiences about design of carbon futures contracts, product pricing, trading rules, risk control mechanisms, investor eligibility management, etc.

Eventually, a unified carbon emission trading system with Chinese characteristics should be built, forming a triopoly with the EUETS and the Chicago Climate Exchange (CCX), thus promoting the green and sustainable development on a global scale.

\section{Conclusions}

In this study, the $\operatorname{GARCH}(1,1)$ and $\operatorname{EGARCH}(1,1)$ models are used to estimate the price volatilities for different exchanges based on the data features of daily returns, and the VaR model is used to calculate the risks in China's carbon trading market. The main results as follows:

(1) The daily returns of China's carbon finance present a sharp peak and heavy tail pattern, which do not follow the normal distribution. The GARCH $(1,1)$ model can well characterize the sharp peak and heavy tail of daily return series for China's carbon finance.

(2) The volatility of returns at different pilot sites measured with the $\operatorname{GARCH}(1,1)$ model finds that the volatility shock decays to varying degrees among different sites. For Shanghai, Guangzhou, and Beijing, the intrinsic shock exerts a prolonged impact on the return volatility.

(3) The $\alpha$ values are all greater than the $\beta$ values for the pilot sites except for Beijing, proving that the carbon price volatility is more likely to be affected by the heterogeneity 
of the external environment for carbon finance market than the role of internal market mechanism.

(4) The VaR model is used to test the market risk of the five exchanges, the result shows that the level of market risk varies among the exchanges in different regions, which are ranked into Shenzhen, Guangdong, Beijing, Hubei, and Shanghai in a descending order of volatility.

(5) The GARCH-VaR risk measurement model is ideal upon validation through the Kupiec failure frequency test.

The paper measures the risks in China's Carbon Financial Market based on GARCH$\mathrm{VaR}$ model. Though periodical achievements have been obtained, the following few questions still request further research. Firstly, the risk measurement model should incorporate other social and policy factors, such as GDP variation, industry structure, etc. Secondly, the general formula employed by the paper in VaR measurement does not distinguish rise risk and fall risk, but measures the general VaR value instead. Therefore, it needs to respectively measure rise risk and fall risk in following sections.

Acknowledgements. The authors are grateful for the financial support provided by the University of Electronic Science and Technology of China, Zhongshan Institute Scientific Research Starting fund for PHD (26-415YKQ12), Zhongshan science and Technology Bureau (2016B2154) and the humanities and social sciences fund of the Ministry of Education (14YJC790172).

\section{REFERENCES}

[1] Alberola, E., Chevallier, J., Chèze, B. (2008): Price drivers and structural breaks in European carbon prices 2005-2007. - Energy Policy 36(2): 787-797.

[2] Bollerslev, T. (1986): Generalized autoregressive conditional heteroskedasticity. - Journal of Econometrics 31(3): 307-327.

[3] Carmona, R., Fehr, M., Hinz, J. (2010): Optimal stochastic control and carbon price formation. - Society for Industrial and Applied Mathematics.

[4] Dutschke, M., Schlamadinger, B., Wong, J. L. P. (2004): Value and risks of expiring carbon credits from CDM afforestation and reforestation. - Social Science Electronic Publishing 5.

[5] Engle, R. F. (1982): Autoregressive Conditional Heteroscedasticity with Estimates of the Variance of United Kingdom Inflation. - Econometrica 50(4): 987-1007.

[6] Ibrahim, B. M., Kalaitzoglou, I. A. (2006): Why do carbon prices and price volatility change? - Journal of Banking \& Finance 63: 76-94.

[7] Kijima, M., Maeda, A., Nishide, K. (2010): Equilibrium pricing of contingent claims in tradable permit markets. - Journal of Futures Markets 30(6): 559-589.

[8] Kupiec, P. (1995): Techniques for Verifying the Accuracy of Risk Measurement Models. - Social Science Electronic Publishing 3(2): 73-84.

[9] Labatt, S., White, R. R. (2011): Carbon finance: the financial implications of climate change. - John Wiley \& Sons.

[10] Larson, D. F., Parks, P. (1999): Risks, Lessons Learned, and Secondary Markets for Greenhouse Gas Reductions. - Policy Research Working Paper.

[11] Laurikka, H., Springer, U. (2003): Risk and return of project-based climate change mitigation: a portfolio approach. - Global Environmental Change 13(3): 207-217.

[12] Mansanet-Bataller, M., Pardo, A., Valor, E. (2006): $\mathrm{CO}_{2}$ Prices, Energy and Weather. Energy Journal 28(3): 73-92.

[13] Markowitz, H. (1952): Portfolio selection. - The Journal of Finance 7(1): 77-91.

[14] Sun, Z. D. (2015): Risk of Trading Market in Carbon Finance. 
[15] Wang, L., Song, Y. (2009): Study on financial innovation and risk prevention of carbon trading in China. - Modern Finance \& Economics 2009(6): 30-34. 